\title{
ASSESSMENT OF THE POSSIBILITY OF USING AN UNMANNED AIRCRAFT CLASS MINI TO ILLUMINATE TARGETS BY LASER
}

\author{
Piotr Kasprzak ${ }^{1}$, Andrzej Rypulak ${ }^{1}$, Tomasz Stolarz $^{1}$ \\ 1 Aviation Faculty, Polish Air Force Academy, ul. Dywizjonu 303 nr. 35, 08-521 Dęblin, Poland \\ * Corresponding author's e-mail: a.rypulak@wsosp.pl
}

Received: 2017.12 .28

Accepted: 2018.03 .30

Published: 2018.06.01

\begin{abstract}
The paper presents the use of the UAV (Unmanned Aerial Vehicle) class mini platform to illuminate targets by laser based on the conducted research and the technical capabilities of the platform. The presented mission planning process by Joint Terminal Attack Controller - JTAC gives you the opportunity to familiarize the subjects of the operation of the troops on the modern battlefield. Research conducted as part of the work have been prepared on the basis of requirements against this type of system specified by the user. Thanks to that, we managed to get results and draw conclusions about the applicability of the UAV class mini to the planned tasks.
\end{abstract}

Keywords: precise attack, unmanned aerial vehicle, illuminate targets, laser guided weapon.

\section{INTRODUCTION}

Pioneering attempts to use "targeting" for armaments were carried out during the First World War. One of the earliest structures of this kind was the American Kettering Bug, an aircraft torpedo bomb developed in 1918 by the Americans. Its flight followed a previously set and stabilized gyroscopically course and the programmed distance, the automatic system shut down the engine and detached the wings, causing the bomb to fall and detonate the 81 kilogram head. During the tests a range of $120 \mathrm{~km}$ was obtained.

The first successful combat constructions emerged during the Second World War. Very successful was German, guided by radio by the operator in the airplane, rocket missile, also classified as guided gliding bomb Henschel Hs 293 (Figure 1).

For the first time the missiles were used in August 1943, when two British ships operating in the waters of the Bay of Biscay were damaged and one was sunk.

The US Army also tested different combat solutions of guided on target bombs. An example was equipped with a television camera TDR-1 bomb, which successfully destroyed anti-aircraft installations in the Pacific. It was this kind of bomb that laid the foundations for today's maneuvering missiles.

Contemporary battlefields are quite different from those of the last World War, and are characterized primarily by actions in urban areas. Hence, there was a need to target and precise attacks without causing additional casualties. Today's precision weapons are rockets and bombs guided by a laser beam or satellite receiver GPS signal. Missiles used for these purposes are essential but not the only element of the system. A very important part of this is the highly qualified staff and support equipment that is used in Close Air Support (CAS) operations, primarily a subsystem illuminating the target. More recently, unmanned aerial vehicles (UAVs) have become increasingly popular in the process of precision targeting $[3,6]$.

\section{PLANNING AND EXECUTION OF TRGET GUIDANCE OPERATION}

Precise systems of modern battlefield play a vital role in ensuring the success of operations, 


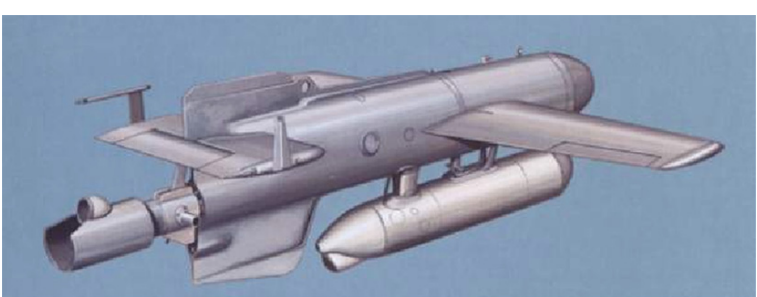

Fig. 1. German radio-guided Henschel rocket missile

ensuring a high probability of achieving the planned effect, while reducing undesirable material damage and civilian casualties.

The technology most commonly used in precision weapons is LASER (Light Amplification by Stimulated Emission of Radiation) [8, 9, 11]. The laser target pointers emit a narrow beam of pulsating energy. By working on near infrared frequencies, the beam is not visible by the human eye. In military applications, lasers are used in laser pointers, devices tracking moving objects, and laser weapons [5]. As part of laser target guidance systems the lasers are used to designate the target (LTD - Laser Target Designator) for devices operating in the mode of searching and receiving the laser beam (Laser Spot Tracker - LST) and Laser Guided Weapons (LGW) [1, 2, 4, 7].

The guidance process in simplification is to illuminate the target with a radius derived from the laser target pointer LTD. Reflected from the target, the radiation is received by the receiver in the missile and serves to guide the missile to the target (Figure 2).

At the time of planning the task, it is necessary to pay attention to the performance of the laser pointer itself. The beam extension angle affects the illuminated area. For example, for a beam of $1 \mathrm{mrad}$ width, at a distance of $1000 \mathrm{me}$ ters, the area indicated by the laser has a diameter of about 1 meter, at a distance of $2000 \mathrm{~m}$ the radius rises to $2 \mathrm{~m}$.

On the modern battlefield, the task of guiding the planes and helicopters rests on specially trained soldiers, the so-called JTACs (Joint Terminal Attack Controller - JTAC) supporting the precise destruction of targets by illuminating them with a laser beam. An example of a missile guided by a laser beam is air-to-ground rocket missile AGM-114 Hellfire [10].

The factor determining the precision and range of guidance, in addition to the level of training of the operator, is the quality of the available equipment. One of the laser target pointers is the

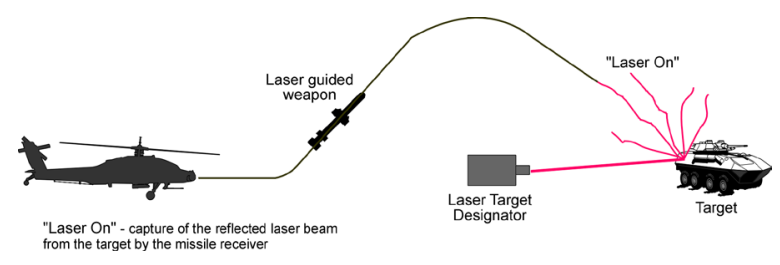

Fig. 2. Scheme of rocket missile guidance to the target using a laser target designator

IZLID 1000P. This is an Infra Red long range laser pointer, used to point both airborne and ground targets. It enables quick switching to illuminate target (IR illuminator) for visual identification using NVG night vision goggles. A comparison of the basic parameters of the IZLID 1000P target pointer and the pointer used in the studies is presented in Table 1.

\section{RESEARCH}

The aim of the study was to evaluate the possibility of using an unmanned aerial vehicle class mini as a platform for carrying the laser target pointer LTD, which, controlled by a ground-based operator, would illuminate the target for efficient targeting of the armament.

As a result of an interview with JTAC personnel pointing aircraft to their targets pointing them from the ground using LSD, the following research tasks were identified:

- A platform selection (BSP) that carries a laser target pointer.

- Laser target pointer selection.

- Integration of the laser target pointer with the carrier.

Table 1. Basic technical parameters of the laser IZLID $1000 \mathrm{P}$ target pointer and pointer used in the tests

\begin{tabular}{|c|c|c|}
\hline Parameter & IZLID 1000P & $\begin{array}{c}\text { Pointer used } \\
\text { in the tests }\end{array}$ \\
\hline Radiated wavelength & $860 \mathrm{~nm}[\mathrm{IR}]$ & $535 \mathrm{~nm}$ \\
\hline Dimensions & $255 \times 58 \times 80 \mathrm{~mm}$ & $\begin{array}{c}160 \times 14 \times 14 \\
\mathrm{~mm}\end{array}$ \\
\hline Output power & max. $990 \mathrm{~mW}$ & $\mathrm{max} 1000 \mathrm{~mW}$ \\
\hline $\begin{array}{c}\text { Nominal Ocular } \\
\text { Hazard Distance }\end{array}$ & $620 \mathrm{~m}$ & $300 \mathrm{~m}$ \\
\hline Weight with batteries & $735 \mathrm{~g}$ & $110 \mathrm{~g}$ \\
\hline Beam width & $1 \mathrm{mrad}$ & $1 \mathrm{mrad}$ \\
\hline $\begin{array}{c}\text { Effectiwe range: } \\
\text { pointer / iluminator }\end{array}$ & $43 / 7 \mathrm{~km}$ & $8 / 2 \mathrm{~km}$ \\
\hline Operating modes & $\begin{array}{c}\text { Low, High, Pulse } \\
4 \mathrm{~Hz}\end{array}$ & Low \\
\hline
\end{tabular}




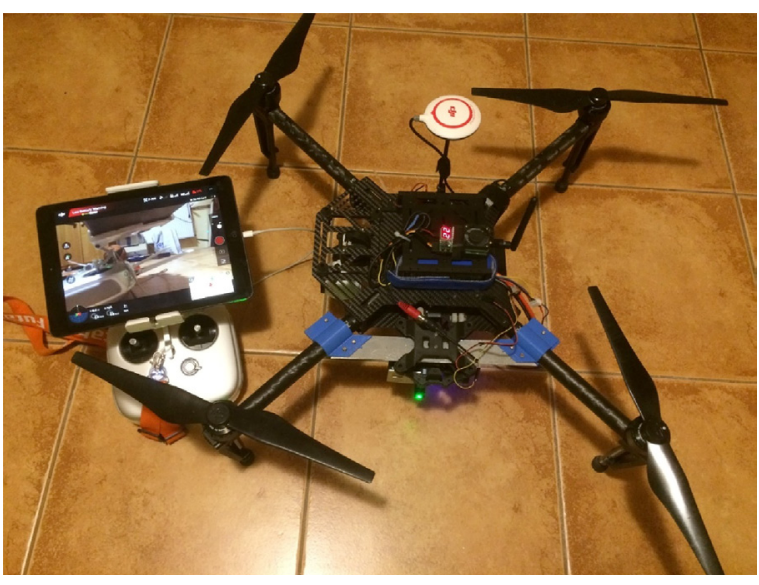

Fig. 3. The platform DJI Matrice 100

- Testing the effectiveness of illuminating of the selected target.

\section{The selection of a platform carrying the laser target pointer}

The basic requirement for the platform is its integration with the laser pointer mounting and stabilization system. Stability of pointing systems is possible thanks to the BSP flight stabilization function, which is implemented using the inertial measurement unit (IMU) and the GPS satellite receiver. Taking into consideration the possibility of steering, lifting, stabilization of flight parameters and retrofitting as a platform, four-rotor BSP DJI Matrice100 was selected (Figure 3), the basic parameters of which are presented in Table 2.

In order to assemble the laser pointer, the BSP Matrice 100 is equipped with an additional twoaxis Tarot T-2D - gimbal, angle stabilization system. It allows mounting the laser pointer and, during the flight, stabilizing the pointer position regardless of the angular position of the carrier. The stabilizer uses a 32-bit processor, an IMU system with a frequency of measurements $2000 \mathrm{~Hz}$. The

Table 2. Basic technical parameters of the DJI Matrice 100

\begin{tabular}{|c|c|}
\hline Parameter & Parameter value \\
\hline Weight (with TB48D battery) & $2431 \mathrm{~g}$ \\
\hline Max. take of weight & $3400 \mathrm{~g}$ \\
\hline Hovering Accuracy (with GPS) & $\begin{array}{c}\text { vertical: } 0,5 \mathrm{~m} ; \\
\text { horizontal: } 2,5 \mathrm{~m}\end{array}$ \\
\hline Max. wind resistance & $10 \mathrm{~m} / \mathrm{s}$ \\
\hline $\begin{array}{c}\text { Hovering time (with TB48D } \\
\text { battery) }\end{array}$ & $\begin{array}{c}\text { no payload: } 28 \mathrm{~min} . ; \\
500 \mathrm{~g} \text { payload: } 20 \mathrm{~min} .\end{array}$ \\
\hline
\end{tabular}

stabilizer head was equipped with a sports camera grip, facing the incident ray emitted by the pointer. With its help, it was possible to pre-identify the position relative to the illuminated target field.

\section{Selection of laser target pointer}

A laser pointer producing a visible beam with a wavelength of $532 \mathrm{~nm}$ in green color (Figure 4) was selected for testing as the pointer of the target. With a power of $5 \mathrm{~mW}$ its range is $30 \mathrm{~km}$ (parameter given by the manufacturer). It is powered by two AAA batteries, and its mass (without batteries) is $60 \mathrm{~g}$. The splitting of the beam, as with the IZLID100, is about a meter at a distance of 1000 meters. It is therefore possible to refer the obtained during the test results to the properties of the professional pointer IZLID 100 , which could be adapted to the flying platform in the future.

In preparation for the tests, it was found that the use of a laser pointer in full configuration, including 2 x AAA batteries with a total voltage of $3 \mathrm{~V}$, increased the gimbal load beyond its ability to stabilize the pointer position. This forced the need to remove the battery and supply power to the pointer from the battery mounted on the platform through a converter, reducing the voltage from 11.2 to $3.0 \mathrm{~V}$.

\section{Course of research}

The tests were conducted in the setting sun, so that the incident laser beam was visible in the outline of the imitated target. Under daylight conditions, the laser pointer of this class is unable to provide a visible beam to the naked eye (Figure 5).

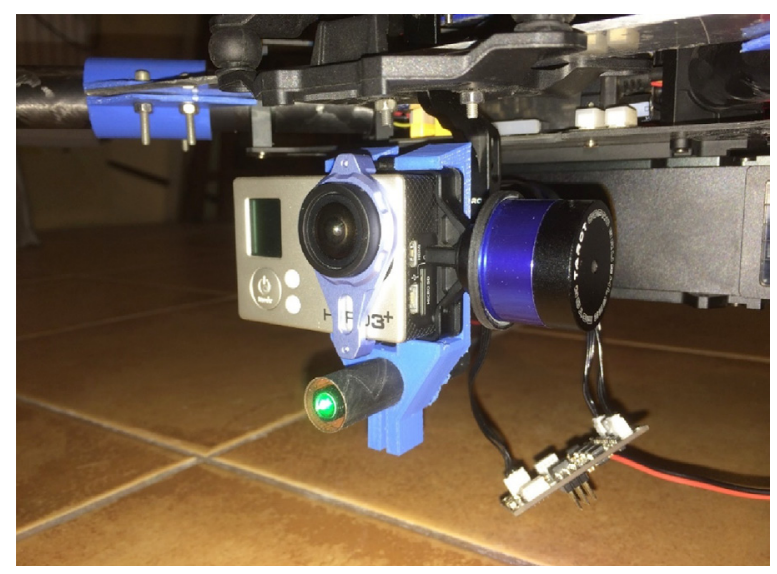

Fig 4. Illuminating and observation system mounted on DJI Matrice 100 


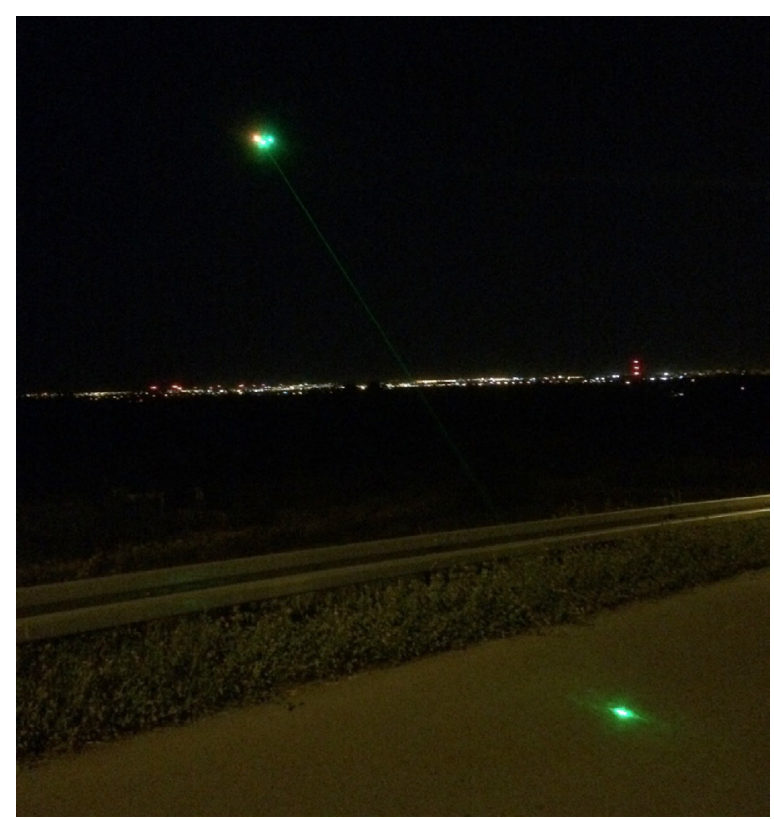

Fig. 5. View of the laser spot that illuminates the target

At the time of the test, the weather conditions give the possibility of a stationary hover for the platform. Wind speed of $2 \mathrm{~m} / \mathrm{s}$ and steady direction. The air temperature was about $20^{\circ} \mathrm{C}$. The illuminated target was imitated by a square with a side of $5 \mathrm{~m}$, defined by a warning tape (Figure 6).

The test was conducted with the use of the DJI Matrice 100 platform, GoPro HERO 3+ sports camera, laser pointer and FPV video relay. It consisted of several attempts to stabilize the laser beam at a constant height and variable distance. The illumination time for each test was 30 seconds. In real conditions, no minimum target lighting time is defined,Under no circumstances was the minimum target illumination standard set, it is dictated by the property of the armaments used. An interview with GLTD II pointer operators showed that the most common time was 8 seconds and the shortest possible operation of the pointer is aimed beyond this value.

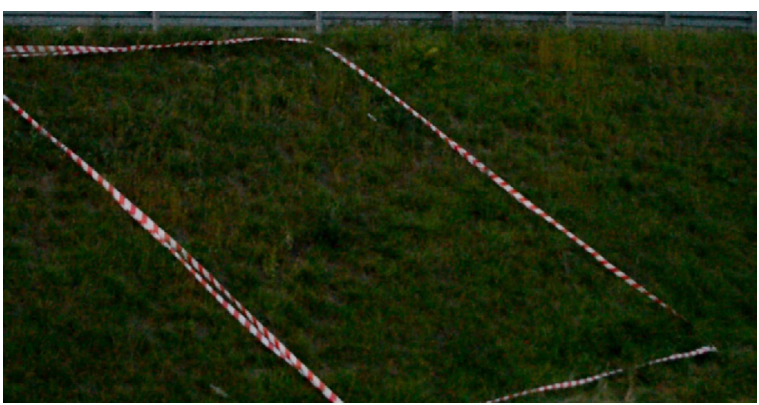

Fig. 6. Imitated target illuminated by laser during tests
Table 3. Test conditions of quality of target illuminating stabilization

\begin{tabular}{|c|c|c|c|}
\hline & $\begin{array}{c}\text { Distance to target } \\
{[\mathrm{m}]}\end{array}$ & $\begin{array}{c}\text { Flight altitude } \\
{[\mathrm{m}]}\end{array}$ & $\begin{array}{c}\text { Wind } \\
\text { speed } \\
{[\mathrm{m} / \mathbf{s}]}\end{array}$ \\
\hline Test I & 100 & 50 & 2 \\
\hline Test II & 300 & 50 & 2 \\
\hline Test III & 500 & 50 & 2 \\
\hline Test IV & 750 & 50 & 2 \\
\hline Test V & 1000 & 50 & 2 \\
\hline Test VI & 1500 & 50 & 2 \\
\hline
\end{tabular}

Testing the quality of stabilization of the laser radiation was performed under the conditions shown in Table 3, wherein for each test, the test was repeated four times.

During the test, the image was displayed on the screen of the carrier manipulator, on which the target was visible, the laser beam spot and the carrier's flight parameters (Figure 7).

After completion of the tests, on the basis of the recorded image, the time of target illumination for the laser beam was specified, and then the percentage of the time to the assumed time for lighting of 30 seconds. This resulted in a percentage of laser stabilization efficiency.

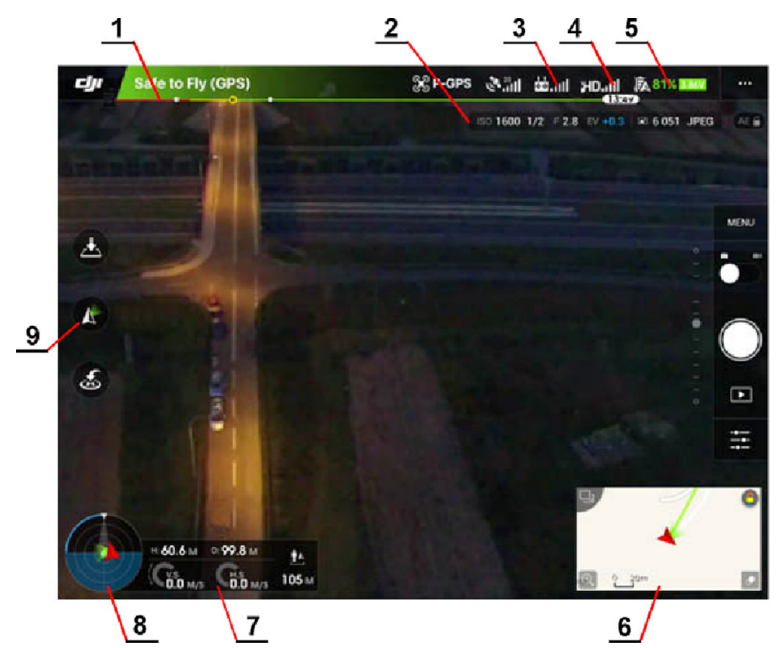

Fig. 7. Operator's manipulator screen view: 1) Progress bar with information about the possibility of further flight, 2) Information about camera settings, 3) Signal strength, 4) Information on the quality of the image being transmitted, 5) Battery charge status of the carrier, 6) Miniature map showing the position of the carrier, 7)Information about height, distance, vertical and horizontal speed flight, 8) Location in space, artificial horizon, 9) Operation type selection menu of the carrier's camcorder 


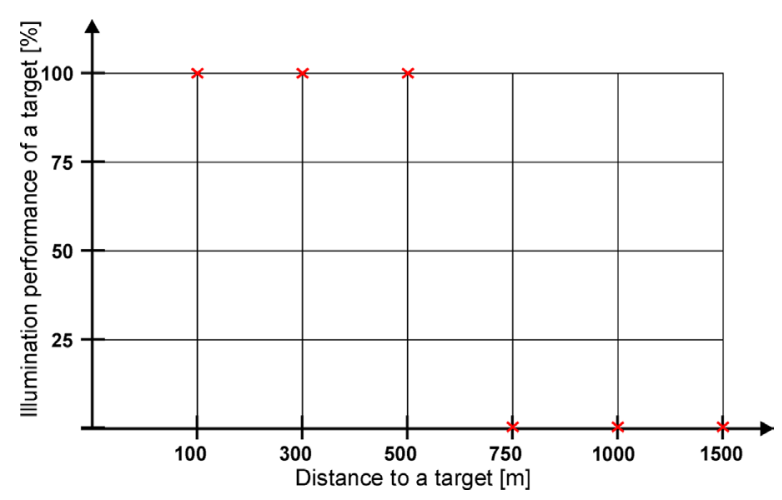

Fig. 8. Illumination performance of a target of $5 \times 5 \mathrm{~m}$ for different distances. Testing conditions: carrier's flight height of $50 \mathrm{~m}$, wind speed of $2 \mathrm{~m} / \mathrm{s}$

\section{CONCLUSIONS FROM THE TEST CONDUCTED}

Obtained results of research were in a synthetic manner shown in Fig. 8.

The first attempt at a target distance of $100 \mathrm{~m}$ and a flight height of $50 \mathrm{~m}$ showed that the time at which the laser beam managed to maintain at every 30 seconds of measurement was $120 \mathrm{~s}$. This means that for $100 \%$ of the laser operation it was possible to illuminate the target steady.

On the second attempt, three times the distance of the laser beam on the target was also equal to the time of its illumination, so the effectiveness of the stabilization was also $100 \%$.

During the third test the distance increased to $500 \mathrm{~m}$. At this distance, the problem becomes the limitation of the range of the laser pointer tilt control. Despite this, the results are still very good. The illumination time of the target was again $100 \%$ of the total laser operating time.

Subsequent attempts at distances of 750 and $1,000 \mathrm{~m}$ resulted in a dramatic drop in target illumination time. This was caused by problems with the range of RC apparatus. Under the conditions given, it was not possible to target the pointer to the target so as to stabilize its position. In each test, the laser spot wandered off the target, changing its position. The attempt at $1500 \mathrm{~m}$ was completely unsuccessful because the radio waves did not reach the receiver of the gimbal control system, which resulted in no response to the operator's command.

It should be noted that when the distance is increased from 100 to $1500 \mathrm{~m}$, the accuracy of aiming and keeping the pointer on the target significantly decreases. This is due to the fact that the accuracy of stabilizing the gimbal position is $0.1^{\circ}$. At a distance of $500 \mathrm{~m}$, the laser spot fluctuations are about $1 \mathrm{~m}$, and at $1500 \mathrm{~m}$ about $3 \mathrm{~m}$. Although the vibrations are not relatively large, they are increased by vibrations, intensified by air movements at a height of $50 \mathrm{~m}$, significantly lowering the threshold of stabilization of the pointer. Moreover, the width of the laser beam itself is already about $2 \mathrm{~m}$. A very simple improvement for the system would be using a carrier equipped with six and not four motors. This would increase the stability and lifting capacity, which, when carrying a professional laser sighting, eg IZLID 1000P weighing $735 \mathrm{~g}$, is important.

\section{SUMMARY}

As a result of the tests, it can be concluded that the UAV class mini can be used to carry a laser target pointer and its effective use for illuminating targets up to $500 \mathrm{~m}$ away from the carrier position.

During the tests, a GoPro HERO 3+ camera was used to transmit a live image that was calibrated with a laser, positioned in one place. The monitor, on which the transmitted image was reproduced, only to a certain point guaranteed accurate observation of the terrain. The solution to this situation would be to connect the receiver FPV to another, a larger monitor, or change GoPro camera to another, with a smaller viewing angle. The test solution was to rotate the dedicated camera to the ZENMUSE platform so that it came with a preview.

At first glance, the result of effective illumination at a distance up to $500 \mathrm{~m}$, especially with the range of e.g. illuminator IZLID 1000P up to $47 \mathrm{~km}$, is very weak. However, taking into account the need to illuminate targets in a built-in area where a terrestrial laser illumination is less useful, the use of target illumination from the drone greatly expands the possibility of attacking targets under these conditions.

However, it is worth remembering that the range of the remote control itself allows for effective control of the Matrice 100 carrier even at distances up to $5 \mathrm{~km}$ from the operator. This gives a fairly large distance from which it is safe to carry out a target illumination operation by a sub-unit having such a device available. Another example where such a solution could be checked is a situation in which a patrol encounters an important target previously unrecognized. Having no time to wait for the operator of the GLTD II, a trained soldier can prepare a mini-unit in a few minutes, let it out in the air and illuminate the target even 
a few kilometers away. Moreover, the use of this platform would significantly reduce the costs of CAS operations. The cost of carrying the Matrice 100 along with the necessary equipment is several thousand dollars and is many times smaller than the cost of the UAV Male or Hale class.

\section{REFERENCES}

1. Agraval V., Goyal V., Dhyani A., Advanced Test System for Comprehensive Characterization of Laser Seekers in the Presence of Countermeasures. Journal of Optoelectronics Engineering, 4 (1), 2016, 5-10.

2. Anderberg B., Wolbarsht M.L., Laser Weapons: The Dawn of a New Military Age. Springer 1992.

3. Department of Defense U.S. Army, Unmanned Aircraft Systems Roadmap 2010-2035. Office of the Secretary of Defense. US Fort Rucker, Alabama. 2010.

4. Integrated target acquisition and fire control systems. AGARD Conference Proceedings 500, February 1992.
5. Joint Tactics, Techniques, and Procedures for Laser Designation Operations. Joint Pub 3-09.1, 28 May 1999.

6. Marshall D.M., Barnhart R.K., Shappee E., Most M., Introduction to unmanned aircraft systems. Second edition. CRD Press 2017.

7. Multi-service Tactics, Techniques, and Procedures for Joint Application of Firepower. JFIRE, January 2016.

8. Sabatini R., Richardson M.A., Airborne Laser Systems Testing and Analysis. AGARDograph Series RTO-AG-300 Vol. 26, January 2010.

9. Sabatini R., Richardson M.A,. Gardi A., Ramasamy S., Airborne laser sensors and integrated systems. Progress in Aerospace Sciences, Volume 79, pages 16-63, November 2015.

10. Tsourdos A., White B., Shanmugavel M., Cooperative Path Planning of Unmanned Aerial Vehicles. Wiley 2011.

11. Ziętek B. Lasery. Wydawnictwo Naukowe Uniwersytety Mikołaja Kopernika 2009. 